\title{
An alternative approach to detect Trypanosoma in Glossina (Diptera, Glossinidae) without dissection
}

\author{
Filipa Ferreira, ${ }^{1}$ Jorge Cano, ${ }^{2}$ Andreia Furtado, ${ }^{3}$ Nicolas Ndong-Mabale, ${ }^{4}$ Pedro Ndong-Asumu, ${ }^{4}$ \\ Agustin Benito, ${ }^{2}$ João Pinto, ${ }^{3}$ Maria Odete Afonso, ${ }^{5}$ Jorge Seixas, ${ }^{1}$ \\ Jorge Atouguia, ${ }^{1}$ Sónia Centeno-Lima. ${ }^{1}$ \\ ${ }^{1}$ Unidade de Clínica das Doenças Tropicais and Centro de Malária e Outras Doenças Tropicais - LA, Instituto de Higiene e \\ Medicina Tropical, Universidade Nova de Lisboa. Rua da Junqueira, 96, 1349-00 Lisboa, Portugal. \\ ${ }^{2}$ Centro Nacional de Medicina Tropical, Instituto de Salud Carlos III, Sinesio Delgado, 4 pabellón 13, 28029 Madrid, Spain. \\ ${ }^{3}$ Centro de Malária e Outras Doenças Tropicais - LA, Instituto de Higiene e Medicina Tropical, Universidade Nova de Lisboa. \\ Rua da Junqueira, 96, 1349-00 Lisboa, Portugal. \\ ${ }^{4}$ Sleeping Sickness National Control Programme, Bata, Equatorial Guinea. \\ ${ }^{5}$ Unidade de Entomologia Médica/UPMM, Instituto de Higiene e Medicina Tropical, Universidade Nova de Lisboa, Rua da \\ Junqueira, 96, 1349-006 Lisboa, Portugal.
}

\begin{abstract}
Background: Determining if a tsetse fly is infected by trypanosomes and thus potentially able to transmit trypanosome-related human and animal diseases is an extremely laborious and time-consuming task to perform, especially under field conditions. In this study we tested a possible alternative approach that uses the entire insect vector for DNA extraction and PCR analysis to detect and identify Trypanosoma spp. in field collected tsetse flies.

Methodology: DNA extraction was performed using a method originally developed for tick DNA extraction followed by PCR detection and identification of Trypanosoma spp.

Results: Two out of 62 flies captured in Equatorial Guinea carried DNA of T. brucei s.I. and Trypanosoma vivax. T. congolense forest, $T$. congolense savannah and $T$. congolense Kilifi were not detected.

Conclusions: The approach we employed allowed the molecular detection and species identification of trypanosomes using the whole vector body for DNA extraction. Although the approach does not give direct information on tsetse infectivity, it provides valuable information about trypanosome species circulating in a tsetse fly vector population. The method allows an effective processing of a large number of field captured tsetse in a central laboratory.
\end{abstract}

Key Words: Glossina, Trypanosoma, PCR, Equatorial Guinea.

J Infect Developing Countries 2008; 2(1):63-67.

Received 7 August 2007 - Accepted 2 January 2008.

Copyright (C) 2007 Ferreira et al. This is an open access article distributed under the Creative Commons Attribution License, which permits unrestricted use, distribution, and reproduction in any medium, provided the original work is properly cited.

\section{Introduction}

African trypanosomes are flagellate protozoa that infect both humans and animals in subSaharan countries. They cause human African trypanosomiasis (HAT, sleeping sickness), and several animal diseases (e. g. nagana).

Without adequate treatment, sleeping sickness is a fatal disease. HAT has made a major comeback in the last decades and WHO estimates that the disease is annually killing 66,000 individuals. Two different forms of the disease exist, caused by two different Trypanosoma brucei sub-species. Trypanosoma brucei rhodesiense is responsible for the acute and severe form of the disease found mainly in East Africa, while Trypanosoma brucei gambiense is responsible for the chronic neurological disease found in West and Central Africa [1].

Tsetse flies (Glossina spp.) are the vectors responsible for the transmission of trypanosome infection in Africa, in an area approaching 10 million $\mathrm{km}^{2}$. The trypanosomes they transmit affect humans directly and through the wasting diseases of the livestock and promote a huge economical loss in the African continent [2].

Understanding the complex interaction between tsetse flies and trypanosomes in a given geographical setting is epidemiologically relevant and a key element for the establishment of rational and effective disease control measures [3]. 
Determining whether a tsetse fly is infected by trypanosomes is extremely laborious and timeconsuming. In classical methods the different potentially infected organs (proboscis, salivary glands and midgut) must be carefully removed through dissection of the vector for direct observation of trypanosomes, immediately after capture [4]. More recently, molecular analysis by PCR methods has been used for trypanosome identification in tsetse organs but these methods still need on-site fly dissection by skilled personnel [5-10].

The present study reports an alternative approach to the detection of trypanosomes in the tsetse. Our method consists of PCR-based detection and identification of trypanosomes using the entire vector. Using this approach in remote locations of endemic African countries where difficult field conditions preclude tsetse dissection, tsetse flies can be collected and stored for months until analysis is performed in central laboratories.

\section{Materials and Methods}

Sampling sites, capture method and processing of tsetse flies

Tsetse flies from Equatorial Guinea (WestCentral Africa) were collected during HAT control activities in Equatorial Guinea in July 2005 (the rainy season) in the partially controlled HAT focus of Campo River (Figure 1). This focus is located around the shores of one of the three main rivers of the country, the Ntem River. The main tsetse fly species present on this focus is Glossina palpalis palpalis, although Glossina caliginea and Glossina tabaniformis are also present. Modified pyramidal traps [11] were employed to capture tsetse flies. Traps were hung at sunrise and checked at sunset during three consecutive days. Collected flies were killed by cold $\left(-20^{\circ} \mathrm{C}\right)$, and on-site fly dissection was not performed. Tsetse were dried in silica gel and stored for molecular studies. The tsetse flies were subsequently identified using a modified entomological key described previously [12 -16].

\section{Sample preparation (DNA extraction)}

DNA was extracted using a slightly modified protocol developed for DNA extraction in ticks [17]. The tsetse flies that had been conserved at $-20^{\circ} \mathrm{C}$ were first washed twice in a $70 \%$ ethanol solution and twice in sterile distilled water. A sterilized blade was used to longitudinally cut each fly into two equal parts. One half of the fly was collected in a $1.5 \mathrm{ml}$ Eppendorf tube, homogenised with a pipette tip in $200 \mu \mathrm{l}$ of PBS and boiled at $100^{\circ} \mathrm{C}$ for 10 minutes. Tubes were left at room temperature for 5 minutes, followed by a short spin to collect drops from the lid. Subsequently, $20 \mu \mathrm{l}$ of $10 \%$ SDS were added. The tubes were vortexed and spun for 5 minutes at $14,000 \mathrm{rpm}$ (or full speed). Two hundred microlitres phenol: chloroform: isoamylalcohol ( $\mathrm{P}: \mathrm{C}: \mathrm{Al}=25: 24: 1 \mathrm{pH} 7,8)$ were added to each tube followed by gentle mixing and spin for 5 minutes at $14,000 \mathrm{rpm}$. The upper phase was transferred to a clean tube, previously filled with 200 $\mu \mathrm{I} P: C: A l$ and gently mixed. Subsequently, tubes were spun for 5 minutes at $14,000 \mathrm{rpm}$ and the upper phase recovered to a clean tube. For DNA precipitation $17.5 \mu \mathrm{l}$ of $3 \mathrm{M}$ Sodium Acetate and $400 \mu \mathrm{l}$ of absolute ethanol were added. The tubes were incubated at $-20^{\circ} \mathrm{C}$ overnight. After the overnight incubation a spinning at $14,000 \mathrm{rpm}$ for 15 minutes was performed. The supernatant was discharged and the pellet washed with $70 \%$ ethanol, dried at $37^{\circ} \mathrm{C}$ in an incubator, and resuspended in $50 \mu$ l of TE (TRIS + EDTA).

Figure 1. Map of mainland Equatorial Guinea showing the tsetse capture site, Campo River.

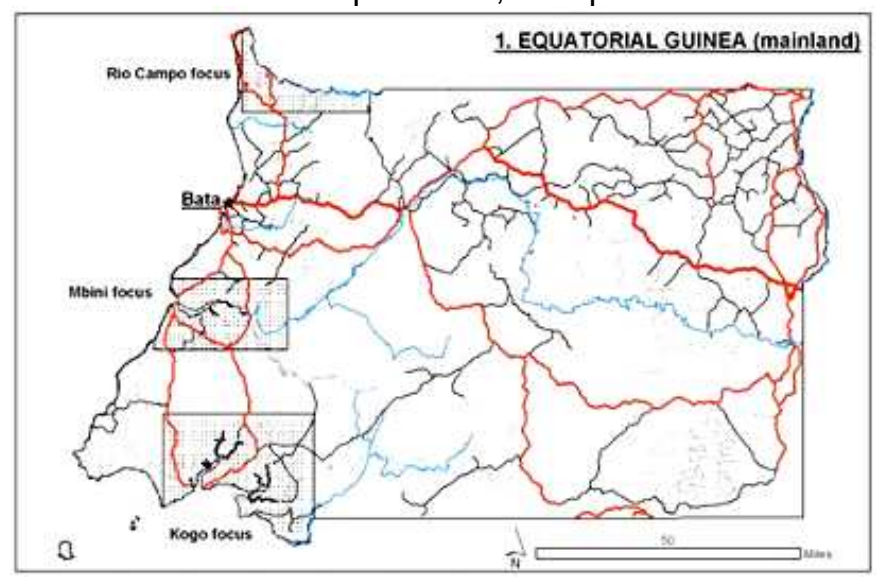

\section{Polymerase Chain Reaction}

To confirm that no PCR inhibition was observed when using the flies' DNA, a PCR reaction targeting the tubulin gene of Glossina was performed as previously described [18].

For trypanosome detection, DNA extracted from the flies was organized in pools of four samples, composed of $1 \mu \mathrm{l}$ of each fly DNA to a final volume of $4 \mu \mathrm{l}$, and then analysed by PCR (ITS and species-specific primers). Whenever a pool yielded a positive amplification signal for the 
primers tested, each sample in that pool was individually tested to validate the result and to identify the positive sample(s) in the pool. In this case, $1 \mu \mathrm{l}$ of fly template DNA was used in PCR. All PCR assays were performed with a final volume of $25 \mu \mathrm{l}$ of reaction mixture.

PCR with ITS1 primers for detection of Trypanosoma spp. was performed as described by Njiru and co-workers [19]. PCR assays with species-specific primers (Table 1) were based on previously described protocols for $T$. congolense ethidium bromide and photographed under UV illumination.

\section{Results}

DNA extracted from all tsetse flies (all identified as Glossina palpalis palpalis) from Rio Campo (Equatorial Guinea) was successfully amplified with the Glossina spp. tubulin primers, confirming that no PCR inhibitors were present in DNA extract.Among the 62 flies, only one tsetse had an amplification signal with ITS primers,

Table 1. Primers used for trypanosome detection.

\begin{tabular}{|c|c|c|c|c|}
\hline Specificity & Code & Primer sequence & Product size(bp) & Reference \\
\hline Trypanosoma spp. & $\begin{array}{l}\text { ITS1 CF } \\
\text { ITS1 BR }\end{array}$ & $\begin{array}{l}\text { 5'- CCGGAAGTTCACCGATATTG -3' } \\
\text { 5'- TTGCTGCGTTCTTCAACGAA -3' }\end{array}$ & Species-specific sizes & 19 \\
\hline T. congolense forest & $\begin{array}{l}\text { TCF1 } \\
\text { TCF2 }\end{array}$ & $\begin{array}{l}\text { 5'- GGACACGCCAGAAGGTACTT -3' } \\
\text { 5'- GTTCTCGCACCAAATCCAAC -3' }\end{array}$ & 350 & 5 \\
\hline T. congolense savannah & $\begin{array}{l}\text { TCS1 } \\
\text { TCS2 }\end{array}$ & $\begin{array}{l}\text { 5'- CGAGCGAGAACGGGCAC -3' } \\
\text { 5'- GGGACAAACAAATCCCGC -3' }\end{array}$ & 316 & 7 \\
\hline T. congolense Kilifi & $\begin{array}{l}\text { TCK1 } \\
\text { TCK2 }\end{array}$ & $\begin{array}{l}\text { 5'- GTGCCCAAATTTGAAGTGAT -3', } \\
\text { 5'- ACTCAAAATCGTGCACCTCG -3' }\end{array}$ & 294 & 5 \\
\hline T. brucei & $\begin{array}{l}\text { TBR1 } \\
\text { TBR2 }\end{array}$ & $\begin{array}{l}\text { 5'- CGAATGAATATTAAACAATGCGCAGT -3' } \\
\text { 5'- AGAACCATTTATTAGCTTTGTTGC -3' }\end{array}$ & 177 & 20 \\
\hline T. vivax & $\begin{array}{l}\text { TVM F } \\
\text { TVM R }\end{array}$ & $\begin{array}{l}\text { 5'- TCGCTACCACAGTCGCAATCGTCGTCTCAAGG -3' } \\
\text { 5'- CAGCTCGGCGAAGGCCACTTGGCTGGGGTG -3' }\end{array}$ & 400 & 21 \\
\hline
\end{tabular}

savannah [7], T. congolense Kilifi [5] and $T$. congolense forest [5], with the following modified amplification conditions: initial step of denaturation at $94^{\circ} \mathrm{C}$ for 5 minutes, followed by 35 cycles at $94^{\circ} \mathrm{C}$ for 1 minute, $60^{\circ} \mathrm{C}$ for 1 minute, $72^{\circ} \mathrm{C}$ for 1 minute, and final extension at $72^{\circ} \mathrm{C}$ for 5 minutes. For $T$. brucei the original amplification conditions [20], were also modified: initial step at $95^{\circ} \mathrm{C}$ for 1 minute, followed by 40 cycles of $95^{\circ} \mathrm{C}$ for 1 minute, $55^{\circ} \mathrm{C}$ for 1 minute, $72^{\circ} \mathrm{C}$ for 1 minute, and final extension at $72^{\circ} \mathrm{C}$ for 10 minutes. T. vivax $\mathrm{PCR}$ was performed using the primers described by Masake and co-workers [21] and the amplification conditions according to Morlais and co-workers [22]. Positive controls (DNA from identified parasites) and negative controls (no template) were used in all PCR assays.

All PCR products obtained were separated by electrophoresis in a $2 \%$ agarose gel, stained with corresponding to T. vivax, as shown in Table 2 .

Samples were subsequently tested with species-specific primers to confirm the sensitivity and specificity of the ITS primers. None of the flies were carrying $T$. congolense forest, savannah or Kilifi DNA. The sample positive for $T$. vivax with ITS primers was also positive with the specific primers for T. vivax. An additional sample was positive for T. brucei s.l. An overall carrier status of $3.23 \%$ of the tsetse was therefore obtained (Table 2). The PCR results did not reveal any multiple trypanosomal infections.

\section{Discussion}

In this study we present a new approach to detect and identify trypanosome parasites in tsetse flies, based on DNA extraction from tsetse entire bodies followed by PCR. This approach has been successfully used in other vector borne diseases, 
such as tick-transmitted or malaria parasites [17, 23].

Our aim was to determine whether the "whole insect body" approach was also feasible in field collected tsetse flies.

Table 2. Identification of trypanosome species by PCR, using ITS1 and species-specific primers, in Glossina palpalis palpalis from Equatorial Guinea ( $\mathrm{N}=$ 62).

\begin{tabular}{lcc}
\hline Trypanosome & $\begin{array}{c}\text { ITS1 primers } \\
\text { (\%) }\end{array}$ & $\begin{array}{c}\text { Species-specific } \\
\text { primers (\%) }\end{array}$ \\
\hline $\begin{array}{l}\text { T. bruceis.l. } \\
\begin{array}{l}\text { T. congolense } \\
\text { forest }\end{array}\end{array}$ & 0 & $1(1.61 \%)$ \\
$\begin{array}{l}\text { T. congolense } \\
\text { savannah }\end{array}$ & 0 & 0 \\
$\begin{array}{l}\text { T. congolense } \\
\text { Kilifi }\end{array}$ & 0 & 0 \\
$\begin{array}{l}\text { T. vivax } \\
\text { Total }\end{array}$ & $1(1.61 \%)$ & 0 \\
\hline
\end{tabular}

The tsetse flies used in the present study were obtained during HAT control activities in Equatorial Guinea, aimed at increasing the efficacy of trapbased tsetse control measures. On-site fly dissection was not performed. The only possibility of acquiring data on the trypanosomes circulating in the tsetse population was to use the conserved flies. For this reason we could not directly compare the sensitivity of our approach with data reported when using microscopy and PCR detection of trypanosomes in dissected tsetse [5 - 10]. Further studies to determine the comparative sensitivity of our approach are needed.

Between the infecting blood meal and maturation into infective stages, trypanosomes have a complex life cycle in tsetse flies. Determining whether a trypanosome present in a tsetse is infective for the vertebrate host requires internal organ localization which then permits the putative identification of the protozoon subgenus. Although this alternative technique only determines the trypanosome carrier status of tsetse flies and the number of positive specimens in our study was very limited, the overall proportion of tsetse flies carrying trypanosomes we found in Rio Campo (3.23\%, 2 out of 62 ) is in the range of the infection rates obtained in studies using PCR techniques in dissected flies from geographically related regions [3]. Furthermore, this alternative technique overcomes the difficulties associated with fly dissection.

The use of ITS1 primers allows a two- to fivefold reduction in sample processing costs when compared to PCR performed with the speciesspecific primers, since the number of reactions required per sample is reduced to a single one [24]. Although this characteristic could render the use of ITS primers more cost-effective, the sensitivity of these primers is known to be lower than the species-specific primers [19]. The very limited number of positive samples (2) we found precludes effectively comparing the performance of the two sets of primers (Table 2).

We believe that one of the main advantages of our approach relates to the field work. In the majority of entomological tsetse surveys, a team of trained technicians goes to the transmission foci and performs tsetse dissection in loco. This usually means at least one week of field work, with related costs (team transportation, per diem, housing, fuel, adequate material and conditions for fly dissection). For many HAT control programs the investment in entomological control activities of this type is too high. With our technique, tsetse flies can be simply collected by unskilled personnel, stored at room temperature and shipped in dry tubes to a central lab where our method can be implemented. We believe that entomological and parasitological surveillance can thus be more cost-effectively achieved.

To our knowledge this is the first report about trypanosome detection and identification in tsetse flies without dissection. Other studies are currently being performed in our laboratory. This method may be integrated as an additional and useful tool in HAT and animal trypanosomiasis control activities.

\section{Acknowledgments}

Part of this work was presented as an oral communication at the 5th European Congress on Tropical Medicine and International Health, 24-28 May 2007, Amsterdam, the Netherlands. We would like to thank Dr. Marcelo Silva (CMDT/IHMT) for providing control DNA for $T$. brucei brucei, Dr. Luís Neves from the Faculdade de Veterinária da Universidade Eduardo Mondlane for providing control DNA for $T$. vivax, $T$. congolense Kilifi and $T$. congolense savannah,and to Prof. António Grácio, Head of the Medical Entomology Unit for providing facilities. SCL was awarded a post-doctoral fellowship by the Portuguese Foundation for Science and Technology. The laboratory work was supported by CMDT-LA. 


\section{References}

1. Atouguia JLM, Kennedy PGE (2000) Neurological aspects of human African trypanosomiasis. In: Davis LE, Kennedy PGE editors. Infectious Diseases of the Nervous System. Oxford: Butterworth-Heinemann. pp. 321-72.

2. Kuzoe FAS, Schofield CJ (2004) Strategic review of traps and targets for tsetse and African trypanosomiasis control. TDR/IDE/TRY/05.1.

3. Morlais I, Grebau P, Bodo JM, Djoha S, Cun G (1998) Characterization of trypanosome infections in wild tsetse flies in Cameroon. Parasitology, 116: 547-554.

4. Lloyd L, Johnson WB (1924) The trypanosome infections of tsetse-flies in Northern Nigeria and new method of estimation. Bull Entomol Res, 14: 265-288.

5. Masiga DK, Smyth AJ, Ayes P, Bromidge TJ, Gibson W (1992) Sensitive detection of trypanosomes in tsetse flies by DNA amplification. Int J of Parasitol, 22: 909-918.

6. Masiga DK, McNamara JJ, Laveissiere C, Trus P, Gibson W (1996) A high prevalence of mixed infections in tsetse flies in Sinfra, Côte d'Ivoire, detected by DNA amplification. Parasitology, 112: 75-80.

7. Majiwa $P A O$, Maina M, Waitumbi JN, Mihok S, Zweygarth E (1993) Trypanosoma (Nannomonas) congolense: molecular characterization of a new genotype from Tsavo, Kenya. Parasitology, 106: 151-162.

8. McNamara JJ, Laveissiere C, Masiga DK (1995) Multiple trypanosome infections in wild tsetse in Côte d'lvoire detected by PCR analysis and DNA probes. Acta Trop, 59: 85-92.

9. Solano P, Argiro L, Reifenberg JM, Yao Y, Duvallet G (1995) Field application of the polymerase chain reaction (PCR) to the detection and characterization in Glossina longipalpis (Díptera: Glossinidae) in Côte d'Ivoire. Mol Ecol, 4: 245-249.

10. Woolhouse MEJ, McNamara JJ, Hargrove JW, Bealby KA (1996) Distribution and abundance of trypanosome (subgenus Nannomonas) infections of tsetse fly Glossina pallidipes in Southern Africa. Mol Ecol, 5: 11-18.

11. Lancien J, Gouteux JP (1986) The pyramidal trap for collecting and controlling tsetse flies (Diptera: Glossinidae). Comparative trials and description of new collecting technics. Trop Med Parasitol, 37: 61-66.

12. Machado A (1954) Révision systématique de glossines du groupe palpalis (Diptera) Publicações Culturais da Companhia de Diamantes de Angola, 22: 189.

13. Potts WH (1973) Glossinidae (tse-tse flies). In Kenneth GVS, Smith editors. Insects and other Arthropods of Medical Importance. London. pp. 209-249.

14. Pollock ME (1982) Description and keys for the identification of Glossina species. In FAO editors. Training Manual for Tsetse Control Personnel. Volume 1 pp.156-201.
15. Jordan AM (1993) Tse-tse flies (Glossinidae). In Richard P Lane, Roger W Crosskey editors. Medical Insects and Arachnids. London: Chapman \& Hall. pp. 333-388.

16. Brunhes J, Cuisance D, Geoffroy B, Hervy JP, Lebbe J (1994) Les glossines ou mouches tsé-tsé. Logiciel d'identification. In Glossine Expert. Manuel illustré d'utilisation, Cirard, Université Paris - VI, ORSTOM. Paris,:160.

17. D'Oliveira $C$, van der Wiede $M$, Jacqiet $P$, Jongejan $F$ (1997) Detection of Theileria annulata by the PCR in ticks (Acari: Ixodidae) collected from cattle in Mauritania. Exp Appl Acarol 21: 279-291.

18. Hao Z, Kasumba I, Aksoy S (2003) Proventriculus (cardia) plays a crucial role in immunity in tsetse fly (Diptera: Glossinidiae). Insect Biochem Mol Biol 33: 1155-1164.

19. Njiru ZK, Constantine CC, Guya S, Crowther J, Kiragu JM, Thompson RCA, Dávila AMR (2005) The use of ITS1 rDNA PCR in detecting pathogenic African trypanosomes. Parasitol Res 95: 186-192.

20. Moser DR, Cook GA, Ochs DE, Baily CP, McKana MR, Donelson JE (1989) Detection of Trypanosoma congolense and Trypanosoma brucei subspecies by DNA amplification using the polymerase chain reaction. Parasitology 99: 57-66.

21. Masake RA, Majiwa PAO, Moloo SK, Makau JM, Njuguna JT, Maina M, Kabata J, Ole-MoiYoi OK, Nantulya VM (1997) Sensitive and specific detection of Trypanosoma vivax using the polymerase chain reaction. Exp Parasitol 85: 193-205.

22. Morlais I, Ravel S, Grebaut P, Dumas V, Cuny G (2001) New molecular marker for Trypanosoma (Duttonella) vivax identification. Acta Trop 80: 207-213.

23. Arez AP, Lopes D, Pinto J, Franco AS, Snounou G, Rosário VE (2000) Plasmodium sp.: optimal protocols for PCR detection of low parasite numbers from mosquito (Anopheles sp.) samples. Exp Parasitol 2000 94: 269272.

24. Desquesnes M, Davila AM (2002) Applications of PCRbased tools for detection and identification of animal trypanosomes: a review and perspectives. Vet Parasitol 11: 213-231.

Corresponding Author: Sónia Centeno-Lima, Unidade de Clínica das Doenças Tropicais and Centro de Malária e Outras Doenças Tropicais-LA, Instituto de Higiene e Medicina Tropical, Universidade Nova de Lisboa. Rua da Junqueira, 96, 1349-00 Lisbon. Phone: +351213652663, Fax: +351213622458, E-mail: slima@inmt.unl.pt

Conflict of interest: No conflict of interest is declared. 